\title{
Arbitragem administrativa À luz da Constituição Federal
}

\section{Administrative arbitration in the light of the Federal Constitution}

\author{
Ricardo MarCondes Martins \\ Doutor em Direito Administrativo pela PUC-SP. Professor de Direito Administrativo da PUC-SP. \\ ORCID: [//orcid.org/0000-0002-4161-9390]. \\ ricmarconde@uol.com.br \\ Recebido em: 04.03.2021 \\ Aprovado em: 01.06.2021 \\ DOI: [https://doi.org/10.48143/rdai.18.rmm]
}

ÁreAS do DIREITO: Administrativo; Arbitragem

Resumo: Este estudo versa sobre a adoção da arbitragem para solução definitiva de conflitos entre a Administração Pública brasileira e o administrado. Apesar de fortes razões sociológicas contrárias à adoção do instituto no Brasil, surpreendentemente, a comunidade jurídica assimilou-o com tranquilidade. Razões dogmáticas, porém, impedem sua adoção. A tese de que ela é possivel quando se trata de interesse secundário é insustentável, pois o interesse secundário só é válido quando coincidente com o primário. A indisponibilidade do interesse público foi contornada pela expressa autorização legislativa. $\dot{E}$ impossivel contornar a supremacia do interesse público sobre o privado, que impede afastar do Judiciário a prerrogativa de dar a última palavra sobre a interpretação das questóes relativas ao interesse público. Por isso, todas as leis autorizadoras da arbitragem administrativa são inconstitucionais.

Palavras-chave: Arbitragem administrativa Interesse público secundário - Interesse público primário - Indisponibilidade do interesse público - Supremacia do interesse público.
ABSTRACT: This study examines the adoption of arbitration for the definitive solution of conflicts between Brazilian Public Administration and its citizens. Despite strong sociological reasons against adopting the institute in Brazil, surprisingly, legal scholars assimilated it with ease. Dogmatic reasons, however, prevent its adoption. The thesis that it is possible when it comes to the secondary interest is untenable, as the secondary interest is only valid when it coincides with the primary one. The unavailability of the public interest was circumvented by explicit legislative authorization term. It is impossible to circumvent the supremacy of the public interest over the private one, which prevents removing the judiciary from having the final word prerogative on the interpretation of matters of the public interest. Therefore, all laws that authorize administrative arbitration are unconstitutional.

KErwords: Administrative arbitration - Secondary public interest - Primary public interest Unavailability of public interest - Supremacy of public interest. 
SumÁRı: 1. Introdução. 2. Delimitação conceitual. 3. Considerações zetéticas. 4. Primeira fase: afronta à indisponibilidade. 4.1. Interesse público secundário e disponibilidade. 4.2. Interesse público primário e disponibilidade legislativa. 5. Segunda fase: afronta à supremacia do interesse público sobre o privado. 6. Conclusões. 7. Referências.

\section{INTRODUÇÃO}

Em 2010, publiquei um estudo sobre a arbitragem no prestigiado periódico "Interesse Público - IP", coordenado pelo Professor Juarez Freitas. Atribuí ao estudo o título "Arbitragem e Administração Pública: contribuição para o sepultamento do tema"1. No ano seguinte, republique-o no prestigiado periódico coordenado pelo Professor Celso Antônio Bandeira de Mello². Em 2015, revi o trabalho e o republiquei, com alterações, no Capítulo 2 de minha obra Estudos de direito administrativo neoconstitucional, capítulo que denominei "Interesse Público e Arbitragem" . Passados seis anos da republicação, e 11 da publicação original, o Professor Rafael Valim convidou-me a revê-lo. Para minha perplexidade, é, até hoje, pela minha pesquisa, senão o único, um dos raros estudos radicalmente contrários à utilização da arbitragem pela Administração brasileira. De lá para cá, houve alteração do direito positivo, e a doutrina brasileira, quase unanimemente, defende-o ardorosamente. De minha parte, depois de participar de vários debates sobre o tema e de refletir bastante sobre ele, revejo meu estudo, mas continuo convencido de que a utilização da arbitragem pela Administração Pública é, tendo em vista a realidade brasileira, incompatível com a Constituição vigente.

\section{DelimitaçÃo conceitual}

O tema da "arbitragem na Administração Pública" exige uma delimitação conceitual importante. De fato, minha tese sobre a invalidade da utilização dessa forma de solução de conflitos se aplica a uma hipótese específica. Os chamados

1. MARTINS, Ricardo Marcondes. Arbitragem e administração pública: contribuição para o sepultamento do tema. Interesse Público, Belo Horizonte, v. 64, p. 85-104, nov.-dez. 2010.

2. MARTINS, Ricardo Marcondes. Arbitragem e administração pública: contribuição para o sepultamento do tema. Revista Trimestral de Direito Público, São Paulo, n. 54, p. 194-209, 2011.

3. MARTINS, Ricardo Marcondes. Estudos de direito administrativo neoconstitucional. São Paulo: Malheiros, 2015. p. 63-81. 
brasileiro, alguém acredite que a Administração sempre escolherá alguém de confiança do povo para decidir sobre o interesse público. $O$ afastamento de todas as regras jurídicas editadas em prol da obtenção da interpretação correta - predicamentos da magistratura, duplo grau de jurisdição, composição plural dos tribunais, tribunais superiores integrados por juristas mais experientes, todo regime do devido processo legal etc. - em prol do interesse do investidor privado causa, no mínimo, perplexidade.

5. Questões dogmáticas, porém, atuam contra a adoção do instituto. Num primeiro momento, afirmou-se que a adoção da arbitragem contrariaria a indisponibilidade do interesse público. Diante dessa tese, difundiu-se o entendimento de que ela só seria possível quando o interesse público fosse "secundário". A tese é insustentável, por uma simples razão: nos termos pacificados na doutrina de quem propôs o conceito de interesse secundário, ele só será válido quando for "coincidente" com o primário. Ora, se é coincidente, e o primário é indisponível, o secundário não pode ser disponível.

6. Muitas vezes, o Estado, em sua missão de realizar o interesse público, tem que dispor do interesse do povo, como ocorre quando aliena um imóvel público. Nessas situações, exige-se que o representante do povo autorize a disposição. Do ponto de vista dogmático, os representantes do povo são os deputados federais, no âmbito da União; estaduais, no âmbito dos Estados; e vereadores, no âmbito dos Municípios. Justamente por isso, sua eleição se dá pelo sistema proporcional e não majoritário. No caso da arbitragem, farta legislação foi editada para autorizar sua utilização no âmbito da administração pública.

7. A autorização legislativa afastou o obstáculo decorrente da indisponibilidade do interesse público. Não afastou, porém, o obstáculo decorrente da supremacia do interesse público sobre o privado. Do ponto de vista dogmático, o Judiciário é o oráculo do Direito, é o órgão encarregado de dar a última palavra sobre a interpretação jurídica. Para que o Judiciário consiga chegar à interpretação correta, há um denso regime jurídico. Não é válido afastar esse denso regime e retirar do oráculo do direito a competência para dar a última palavra sobre a interpretação jurídica apenas para satisfazer o interesse privado. A supremacia do interesse público sobre o privado não permite, concluiu-se, a adoção da arbitragem pela Administração Pública.

\section{REFERÊNCIAS}

ACCIOLY, Hildebrando. Tratado de direito internacional público. São Paulo: Quartier Latin, 2009. v. 3.

ALESSI, Renato. Principi di diritto amministrativo. Milano: Giuffrè, 1966. v. I. 
ALESSI, Renato. Instituciones de derecho administrativo. Trad. Buenaventura Pellisé Prats. Barcelona: Bosch, 1970. t. I.

ALEXY, Robert. Teoría de los derechos fundamentales. Trad. Ernesto Garzón Valdés. 3. reimpr. Madri: Centro de Estudios Políticos y Constitucionales, 2002.

BALLOUK FILHO, Benedito Marques; KUNTZ, Ronald A. Corrupção politica: a luta social pelo resgate da dignidade no exercício do poder. São Paulo: Madras, 2008.

BANDEIRA DE MELLO, Celso Antônio. Apontamentos sobre a teoria dos órgãos públicos. Revista de Direito Administrativo e infraestrutura, São Paulo, ano 2, n. 04, p. 423-434, jan.-mar. 2018.

BANDEIRA DE MELLO, Celso Antônio. Serviço público e atividade econômica: serviço postal. In: BANDEIRA DE MELLO, Celso Antônio. Grandes temas de direito administrativo. São Paulo: Malheiros, 2009.

BANDEIRA DE MELLO, Celso Antônio. Compromisso arbitral - nulidade na esfera do direito administrativo - reajuste de preço com base na variação do dólar: nulidade - desvio de poder. Revista Trimestral de Direito Público, São Paulo, v. 39, p. 116-126, 2002.

BANDEIRA DE MELLO, Celso Antônio. Curso de direito administrativo. 34. ed. São Paulo: Malheiros, 2019.

BANDEIRA DE MELLO, Celso Antônio. Mandado de segurança contra denegação ou concessão de liminar. Revista de Direito Administrativo e Infraestrutura, São Paulo, ano 3, n. 11, p. 441-449, out.-dez. 2019.

BANDEIRA DE MELLO, Celso Antônio. Juizo liminar: poder-dever de exercício do poder cautelar nessa matéria. Revista Trimestral de Direito Público, São Paulo, n. 3, p. 106-116, 1993.

BANDEIRA DE MELLO, Celso Antônio. Introdução. In: ATALIBA, Geraldo (Coord.). Elementos de direito tributário. São Paulo: Ed. RT, 1978.

BATISTA JÚNIOR, Onofre Alves. Transações administrativas. São Paulo: Quartier Latin, 2007.

BITENCOURT NETO, Eurico. Concertação administrativa interorgânica. São Paulo: Almedina, 2017.

BOURDIEU, Pierre; PASSERON, Jean-Claude. A reprodução: elementos para uma teoria do sistema de ensino. 2. ed. Trad. Reynaldo Bairão. Rio de Janeiro: Vozes, 2009.

CARNELUTTI, Francesco. Sistema de direito processual civil. Trad. Hiltomar Martins Oliveira. 2. ed. São Paulo: Lemos e Cruz, 2004. v. 1.

CARVALHO, Márcia Haydée Porto de. Hermenêutica constitucional. Florianópolis: Obra Jurídica, 1997.

CIRNE LIMA, Ruy. Princípios de direito administrativo. 7. ed. São Paulo: Malheiros, 2007.

FAORO, Raymundo. Os donos do poder: formação do patronato político brasileiro. 3. ed. 9. reimpr. São Paulo: Global, 2001. 
FREITAS, Fernanda Martins. Mediação na Administração Pública. Revista Internacional de Direito Público, Belo Horizonte, ano 4, n. 06, p. 189-219, jan.-jun. 2019.

FERRAZ JR, Tercio Sampaio. Introdução ao estudo do direito: técnica, decisão dominação. 5. ed. São Paulo: Atlas, 2007.

FERRAZJR, Tercio Sampaio. Estudos de filosofia do direito. 3. ed. São Paulo: Atlas, 2009.

FERRAZ JR., Tercio Sampaio. Teoria da norma jurídica. 4. ed. Rio de Janeiro: Forense, 2002.

FRIEDMAN, Milton; FRIEDMAN, Rose. Libertad de elegir. Trad. Carlos Rocha Pujol. Madrid: Faes, 2008.

GONÇALVES, Reinaldo. Globalização e desnacionalização. 2. ed. São Paulo: Paz e Terra, 2006.

HACHEM, Daniel Wunder. Principio da supremacia do interesse público. Belo Horizonte: Fórum, 2011.

HARVEY, David. O neoliberalismo: história e implicações. Trad. Adail Sobral e Maria Stela Gonçalves. São Paulo: Loyola, 2008.

HAYEK, Friedrich A. Los fundamentos de la libertad. Trad. José Vicente Torrente. 8. ed. Madrid: Unión Editorial, 2008.

HAYEK, Friedrich A. Principios de un orden social liberal. In: HAYEK, Friedrich A. Estudios de filosofía política y economía. Trad. Juan Marcos de la Fuente. Madrid: Unión Editorial, 2007.

HOLANDA, Sérgio Buarque de. Raizes do Brasil. 26. ed. 17. reimpr. São Paulo: Companhia das Letras, 2003.

HOUAISS, Antônio; VILLAR, Mauro de Salles (Eds.). Dicionário Houaiss da Lingua Portuguesa. Rio de Janeiro: Objetiva, 2001.

KLEIN, Naomi. A doutrina do choque: a ascensão do capitalismo de desastre. Trad. Vania Cury. Rio de Janeiro: Nova Fronteira, 2008.

MARTÍN-RETORTILLO, Sebastián. Sentido y formas de la privatización de la administración pública. In: Os caminhos da privatização da administração pública: IV colóquio luso-espanhol de direito administrativo. Coimbra: Coimbra, 2001, p. 19-30.

MARTINS, Ricardo Marcondes. Arbitragem e administração pública: contribuição para o sepultamento do tema. Interesse Público, Belo Horizonte, v. 64 , p. 85-104, nov.-dez. 2010.

MARTINS, Ricardo Marcondes. Arbitragem e administração pública: contribuição para o sepultamento do tema. Revista Trimestral de Direito Público, São Paulo, n. 54, p. 194-209, 2011.

MARTINS, Ricardo Marcondes. Estudos de direito administrativo neoconstitucional. São Paulo: Malheiros, 2015.

MARTINS, Ricardo Marcondes. Administração Pública consensual: o que mudou com as alterações da LINDB? Revista Brasileira de Infraestrutura, Belo Horizonte, ano 9, n. 18, p. 11-22, jul.-dez. 2020. 
MARTINS, Ricardo Marcondes. Efeitos dos vícios do ato administrativo. São Paulo: Malheiros, 2008.

MARTINS, Ricardo Marcondes. Regulação administrativa a luz da Constituição Federal. São Paulo: Malheiros, 2011.

MARTINS, Ricardo Marcondes. Teoria jurídica da liberdade. São Paulo: Contracorrente, 2015.

MARTINS, Ricardo Marcondes. Teoria geral da interpretação jurídica: considerações críticas à obra de Black. Revista de Direito Administrativo e Infraestrutura, São Paulo, ano 1, v. 3, p. 299-331, out.-dez. 2017.

MAYER, Otto. Derecho administrativo alemán. Trad. Horacio H. Heredia e Ernesto Krotoschin. Buenos Aires: Depalma, 1949. t. I.

MAZZUOLI, Valerio de Oliveira. Curso de direito internacional público. 7. ed. 2. tir. São Paulo: Ed. RT, 2013.

MÜLLER, Friedrich. O novo paradigma do direito: introdução à teoria e metódica estruturantes do direito. Trad. Rossana Ingrid Jansen dos Santos et al. São Paulo: Ed. RT, 2007.

OLIVECRONA, Karl. Linguagem juridica e realidade. Trad. Edson L. M. Bini. São Paulo: Quartier Latin, 2005.

REZEK, José Francisco. Direito internacional público. 8. ed. São Paulo: Saraiva, 2000.

SOUZA, Luciane Moessa de. Meios consensuais de solução de conflitos envolvendo entes públicos: negociação, mediação e conciliação na esfera administrativa $e$ judicial. Belo Horizonte: Fórum, 2012.

STUART MILL, John. A liberdade. Trad. Eunice Ostrensky. São Paulo: Martins Fontes, 2000.

STUART MILL, John. Principios de economía politica. Madrid: Fundación Ico, 2007.

TÁCITO, Caio. Arbitragem nos litígios administrativos. In: TÁCITO, Caio. Temas de direito público: estudos e pareceres - v. 3. Rio de Janeiro: Renovar, 2002. v. 3. 


\section{Pesquisas do Editorial}

\section{Veja também Doutrinas relacionadas ao tema}

- Arbitragem e Administração Pública um panorama global, de João Pedro Accioly - RArb 56/143-178 (DTR|2018|10268);

- Arbitragem no Setor Público: uma visão panorâmica, de Evelin Teixeira de Souza Alves RDE21/171-190 (DTR|2016|24757);

- Da efetividade do Direito Administrativo à efetividade da(s) justiça(s) administrativa(s), de Ricardo Pedro - RPC 8/139-157 (DTR|2018|22725);

- Notas sobre Arbitragem Administrativa no Direito Português, de Manuel Pereira Barrocas RArb 56/265-276 (DTR|2018|10283); e

- 0 cabimento da Arbitragem no Direito Administrativo à luz do principio da indisponibilidade: 0 interesse público exige intervenção jurisdicional?, de Luzardo Faria - RArb 65/127-152 (DTR|2020|7569). 